\title{
Assessment of Prunus Rootstock Accessions Using Chloroplast and Nuclear Microsatellites
}

\author{
Chunxian Chen, Lorraine Rodriguez-Bonilla, and Thomas G. Beckman \\ U.S. Department of Agriculture, Agricultural Research Service, Southeastern Fruit and Tree Nut \\ Research Laboratory, 21 Dunbar Road, Byron, GA 31008
}

\begin{abstract}
AdDitional INDEX wORDs. interspecific hybrid, maternal lineage, phylogenetic analysis, simple sequence repeat
Abstract. A rootstock collection of Prunus species and hybrids is maintained at the U.S. Department of Agriculture stone fruit breeding program at Byron, GA. We genotyped 66 Prunus rootstock accessions and clones using chloroplast and nuclear microsatellites in this study. Chloroplast microsatellites revealed that the accessions belong to four previously defined maternal lineage groups (MLG-1 to -4) and five new ones (MLG-9 to -13). MLG-1 and -2 share the same chloroplast alleles of 'Chinese Cling' peach (Prunus persica) derived scions and American scions and rootstocks related to early European introductions, respectively. MLG-3 included 'Guardian' rootstock and its descendants. MLG-4 had a single genotype, 'Okinawa', that is the maternal parent of 'Flordaking'. MLG-9 and MLG-11 to -13 included hybrids with different plums (Prunus salicina, Prunus cerasifera, Prunus tomentosa, or Prunus angustifolia) in their maternal parentage. MLG-10 included hybrids from almond (Prunus. dulcis) in the maternal parentage. The neighbor-joining phylogenetic tree based on nuclear microsatellite genotyping data showed several clusters. Cluster I included only one scion cultivar Elberta from MLG-1. Clusters II, III, and V contained peach accessions mostly in MLG-2. Clusters IV and VI included accessions mostly in MLG-3. Cluster VII included most accessions of plumpeach hybrid origin and those found within MLG-13. Cluster VIII was found to be mixed with different plum-peach hybrids and hybrids from other Prunus species, most of which were found in MLG-10, -11, and -12. Most accessions in Cluster IX were related to plums in MLG-11 and a few accessions in MLG-9.
\end{abstract}

Peach (P. persica) and other stone fruit (Prunus sp.) scions are grafted onto rootstocks that serve as the foundation for tree architecture. Rootstocks also play primary roles in plant health by providing resistance to soilborne diseases and pests that do not exist in the scions. Stone fruit rootstock breeding programs have released and/or tested many rootstocks (Beckman, 1998; Beckman and Pusey, 2001; Beckman et al., 2008, 2012; Jimenez et al., 2011; Orazem et al., 2012; Ramming and Tanner, 1983; Sherman et al., 1991). Many of the released rootstocks were bred and tested primarily for peach, improving tree adaptation and enhancing competitiveness of commercial production in nonnative, less favorable regions, such as the southeastern United States (Beckman and Pusey, 2001; Okie et al., 1994; Sharpe, 1974). Elite Prunus rootstock accessions and hybrids maintained in these programs are valuable resources and worthy of genotyping. Utilizing molecular evaluation data allow us to better reveal their phylogenetic relationships and authenticate their identity.

Peach and other Prunus rootstocks have been previously genotyped using simple sequence repeats [SSRs (also known as microsatellites)] and other types of molecular markers to reveal genetic clustering and identification (Bouhadida et al., 2009; Liu et al., 2007; Lu et al., 1996), or construct genetic maps (Blenda et al.,

Received for publication 24 Sept. 2021. Accepted for publication 10 Dec. 2021. Published online 4 February, 2022.

The research was partly supported by the U.S. Department of Agriculture (USDA) National Program of Plant Genetic Resources, Genomics and Genetic Improvement (Project number: 6042-21000-005-00D). The authors thank Minling Zhang for DNA preparation and microsatellite genotyping. This article reports the results of research only. Mention of a trademark or proprietary product is solely for the purpose of providing specific information and does not constitute a guarantee or warranty of the product by the USDA and does not imply its approval to the exclusion of other products that may also be suitable. C.C. is the corresponding author. E-mail: chunxian.chen@usda.gov.

This is an open access article distributed under the CC BY-NC-ND license (https://creativecommons.org/licenses/by-nc-nd/4.0/).
2007). Liu et al. (2007) identified seven peach rootstocks, 'Bailey', 'Halford', 'Lovell', 'Nemaguard', 'Nemared', 'Guardian', and 'S-37' using eight nuclear SSR markers that exhibited high reproducibility and were able to discriminate and cluster individuals into five groups (Liu et al., 2007). Using 40 random amplified polymorphic DNA markers, 18 peach rootstock cultivars were clustered in accord with their putative pedigrees (Lu et al., 1996).

Recently Prunus chloroplast SSR (cpSSR) markers were developed, and eight polymorphic ones selected to genotype peach scion accessions in the U.S. Department of Agriculture (USDA) Agricultural Research Service (ARS) stone fruit breeding program at Byron, GA. Eight unique maternal lineage groups (MLGs) were found among the accessions (Chen and Okie, 2017). Likewise, peach nuclear SSR (ncSSR) markers were developed and characterized with additional genomic and amplicon information for optimal selection of SSR markers (Chen et al., 2014). Twenty ncSSR polymorphic markers were selected to decipher the genetic relationship and parentages of historical peaches (Chen and Okie, 2021). In this study, we genotyped Prunus rootstock accessions and clones maintained in the USDA-ARS program in Byron, GA, using the same eight cpSSR and 20 ncSSR markers, to assess their maternal and phylogenetic relationship, and to authenticate clones as well.

\section{Materials and Methods}

Materials. The 66 accessions and clones (Table 1) used in this study were maintained at the USDA-ARS Southeastern Fruit and Tree Nut Research Laboratory stone fruit breeding program at Byron, GA. They were divided into five types: peach (P), almond $(P$. dulcis $) \times$ peach hybrid (AP), peach $\times$ almond hybrids $(\mathrm{PA})$, plum $(P$. salicina, $P$. cerasifera, $P$. tomentosa, or $P$. angustifolia) hybrid (MH), and plum $\times$ peach hybrid (MP). Because of the limited numbers, AP and PA were grouped together 
Table 1. Summary of 66 Prunus rootstock accessions and clones genotyped in this study.

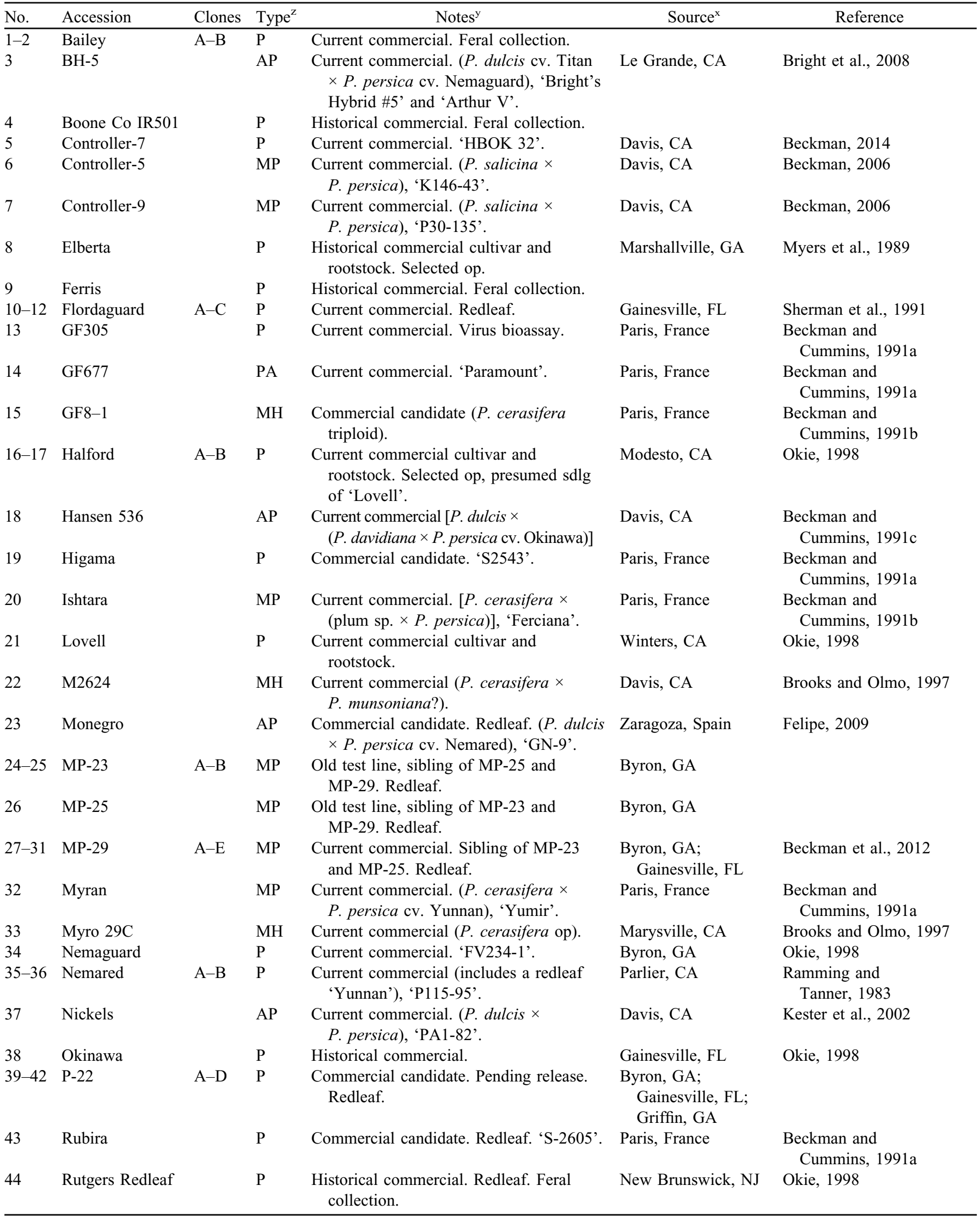


Table 1. (Continued)

\begin{tabular}{|c|c|c|c|c|c|c|}
\hline No. & Accession & Clones & Type $^{z}$ & Notes $^{y}$ & Source $^{\mathrm{x}}$ & Reference \\
\hline $45-47$ & SC3-17-7 & $\mathrm{A}-\mathrm{C}$ & $\mathrm{P}$ & $\begin{array}{l}\text { Current commercial. 'BY520-9' and } \\
\text { Guardian }^{\mathrm{TM}} \text {. }\end{array}$ & $\begin{array}{l}\text { Byron, GA; } \\
\text { Clemson, SC }\end{array}$ & Okie et al., 1994 \\
\hline 48 & Shalil & & $\mathrm{P}$ & $\begin{array}{l}\text { Historical commercial. 'PI36485' and } \\
\text { 'PI63850'. }\end{array}$ & Kurram Valley, India & \\
\hline $49-51$ & Sharpe & $\mathrm{A}-\mathrm{C}$ & MH & $\begin{array}{l}\text { Commercial candidate. (P. angustifolia } \\
\text { hybrid?), 'FLA1-1'. }\end{array}$ & $\begin{array}{l}\text { Byron, GA; } \\
\text { Gainesville, FL }\end{array}$ & Beckman et al., 2008 \\
\hline 52 & Siberian C & & $\mathrm{P}$ & Current commercial. Feral collection. & Harrow, Canada & Okie, 1998 \\
\hline 54 & SL1089 & & $\mathrm{P}$ & $\begin{array}{l}\text { Test line, selected op from B594520-9, } \\
\text { sibling of SC3-17-7, SL1090, SL2170, } \\
\text { and SL2891. }\end{array}$ & Byron, GA & \\
\hline 55 & SL1090 & & $\mathrm{P}$ & $\begin{array}{l}\text { Test line, selected op from B594520-9, } \\
\text { sibling of SC3-17-7, SL1089, SL2170, } \\
\text { and SL2891. }\end{array}$ & Byron, GA & \\
\hline 57 & SL2891 & & $\mathrm{P}$ & $\begin{array}{l}\text { Test line, selected op from B594520-9, } \\
\text { sibling of SC3-17-7, SL1089, SL1090, } \\
\text { and SL2170. }\end{array}$ & Byron, GA & \\
\hline $58-60$ & $\mathrm{TN}$ & $1-3$ & $\mathrm{P}$ & $\begin{array}{l}\text { Historical commercial candidate. Feral } \\
\text { collection. }\end{array}$ & Byron, GA & \\
\hline 61 & TN IR1258-2 & & $\mathrm{P}$ & $\begin{array}{l}\text { Historical commercial candidate. Feral } \\
\text { collection. }\end{array}$ & Byron, GA & \\
\hline 62 & TN IR282-2 & & $\mathrm{P}$ & $\begin{array}{l}\text { Historical commercial candidate. Feral } \\
\text { collection. }\end{array}$ & Byron, GA & \\
\hline 63 & TN Seed Blk & & $\mathrm{P}$ & $\begin{array}{l}\text { Historical commercial candidate. Feral } \\
\text { collection. }\end{array}$ & Byron, GA & \\
\hline
\end{tabular}

as PA for all statistical analyses. Most of them were peach rootstock accessions and clones and several were scion cultivars but also used as rootstocks at some time (e.g., Lovell, a canning peach; Elberta, a well-recognized historical peach). To simplify the narrative, phrases with "rootstocks" or "rootstock accessions" in this article included the several scion accessions. Among the accessions, 'Bailey', 'Flordaguard', 'Halford', 'MP-23', 'MP-29', 'Nemared', 'P-22', 'SC3-17-7', 'Sharpe', and 'TN' included multiple copies or clones (suffixed with $\mathrm{A}, \mathrm{B}, \ldots$ or $1,2, \ldots$ ) for clonal verification. A few accession names contained spaces that were replaced with underscores for statistical software computation, so those with underscores or spaces are the same. Genomic DNAs were isolated from 200-mg young leaves using a cetyltrimethylammonium bromide protocol (Doyle and Doyle, 1987).

SSR PRIMERS, GENOTYPING, AND SCORING PROCEDURE. The eight cpSSR and $20 \mathrm{ncSSR}$ markers used in this study were described and used previously (Chen and Okie, 2017, 2021). Genotyping was performed on an eight-capillary sequencing instrument (Applied Biosystems 3500 Genetic Analyzer; Thermo Fisher Scientific, Waltham, MA). Alleles of cpSSR and ncSSR makers were scored into a tabulated format, respectively, using genotype analysis software (GeneMarker; SoftGenetics, State College, PA) as previously described (Chen and Okie, 2017, 2021).

SSR ALLELE DATA ANALYSIS. The cpSSR and ncSSR allele tables each were converted to the format required by PowerMarker [ver. 3.25 (Liu and Muse, 2005)] and GenAIEx [ver. 6.5 (Peakall and Smouse, 2006, 2012)], respectively. PowerMarker was used to calculate major allele frequency (MAF), genotype number detected (GN), allele number detected (AN), gene diversity (GD), heterozygosity $(\mathrm{H})$, polymorphism information content (PIC), and inbreeding coefficient (F). Also shared alleles and Euclidean genetic distances were calculated among the 
accessions to determine the distances based neighbor-joining (NJ) phylogenetic trees with robustness of branches tested with 1000 bootstraps and displayed using TreeView (Page, 1996). GenAIEx was used to perform principal coordinate analysis (PCoA) of unique accessions with the standardized pairwise genetic distance matrixes and draw the PCoA chart to show the coordinated partitions, respectively. Only the first clone in each of the accessions with multiple clones was kept in the PCoA analysis, and the other identical clones were excluded. Several $\mathrm{R}$ packages, including poppr (Kamvar et al., 2014), adegenet (Jombart, 2008), and ggplot2 (Wickham, 2016), were used for principal component analysis (PCA) of the ncSSR data. The GenAlEx-formatted allele table was converted to a genind object in poppr. Missing data in individuals were replaced with the mean allele frequencies using adegenet. The PCA was developed using the stats package and visualized using ggplot2.

\section{Results and Discussion}

CPSSR AND NCSSR GENOTYPING DATA SUMMARY. The sUmmary showed that genetic diversity values vary among the SSR markers (Table 2). Among the ncSSR primers, CX2A01, CX2D10, and CX3A02 detected the highest GN and AN in the samples (20 and 14, 19 and 15, and 17 and 18, respectively), whereas CX2B12, CX6H11, and CX1G06 detected the lowest (four and three, six and five, and six and five, respectively). The PIC values of CX2A01, CX1E06, and CX2D10 (0.79, 0.74, and 0.74 , respectively) were among the highest, and those of CX2B12, CX3B06, and CX1H09 $(0.38,0.38$, and 0.39, respectively) among the lowest. All the cpSSR alleles were in haploid form, so all GN and AN were the same with each marker. CXcp62273 detected the highest GN and AN (seven).

MLGS BASED ON CPSSR. Based on clusters constructed with alleles detected by the cpSSR, a total of nine MLGs were found (Fig. 1), including MLG-1 to -4 previously defined (Chen and Okie, 2017), and new MLG-9 to -13. All 13 MLGs and their alleles detected by the eight cpSSR primers were listed (Table 3 ), although no genotype in MLG-5 to -8 was found in this collection. The four cultivars in MLG-1 had the same chloroplast alleles as detected in most scion cultivars that were derived from Chinese Cling or its offspring, including Elberta (Chen and Okie, 2017). Those in MLG-2 shared the same maternal lineage as

Table 2. Summary of chloroplast (cp) and nuclear (nc) simple sequence repeat (SSR) marker genotyping data collected from Prunus rootstock accessions. ${ }^{\mathrm{z}}$

\begin{tabular}{|c|c|c|c|c|c|c|c|}
\hline Marker & MAF & $\mathrm{GN}$ & $\mathrm{AN}$ & GD & $\mathrm{H}$ & $\mathrm{PIC}$ & $\mathrm{F}$ \\
\hline \multicolumn{8}{|l|}{ cpSSR } \\
\hline CXcp01488 & 0.44 & 6 & 6 & 0.72 & 0.00 & 0.68 & 1.00 \\
\hline CXcp05368 & 0.53 & 5 & 5 & 0.65 & 0.00 & 0.61 & 1.00 \\
\hline CXсp58614 & 0.65 & 5 & 5 & 0.54 & 0.00 & 0.51 & 1.00 \\
\hline CXсp60541 & 0.38 & 6 & 6 & 0.74 & 0.00 & 0.70 & 1.00 \\
\hline CXcp62273 & 0.38 & 7 & 7 & 0.73 & 0.00 & 0.69 & 1.00 \\
\hline CXcp76664 & 0.59 & 6 & 6 & 0.61 & 0.00 & 0.58 & 1.00 \\
\hline Mean & 0.47 & 6 & 6 & 0.68 & 0.00 & 0.64 & 1.00 \\
\hline \multicolumn{8}{|l|}{$\mathrm{ncSSR}$} \\
\hline CX1B09 & 0.49 & 7 & 5 & 0.59 & 0.22 & 0.50 & 0.62 \\
\hline CX1E06 & 0.33 & 14 & 7 & 0.78 & 0.33 & 0.74 & 0.58 \\
\hline CX2E08 & 0.55 & 11 & 6 & 0.63 & 0.27 & 0.60 & 0.57 \\
\hline CX2B12 & 0.67 & 4 & 3 & 0.46 & 0.20 & 0.39 & 0.58 \\
\hline $\mathrm{CX} 3 \mathrm{~A} 02$ & 0.53 & 17 & 18 & 0.67 & 0.20 & 0.64 & 0.71 \\
\hline CX3F03 & 0.52 & 14 & 13 & 0.65 & 0.22 & 0.61 & 0.66 \\
\hline CX3H09 & 0.77 & 14 & 11 & 0.41 & 0.27 & 0.40 & 0.34 \\
\hline CX3F11 & 0.44 & 12 & 8 & 0.75 & 0.18 & 0.72 & 0.76 \\
\hline CX2A01 & 0.34 & 19 & 14 & 0.80 & 0.27 & 0.78 & 0.67 \\
\hline CX2B03 & 0.45 & 15 & 8 & 0.72 & 0.32 & 0.69 & 0.56 \\
\hline CX2D10 & 0.37 & 19 & 15 & 0.75 & 0.24 & 0.72 & 0.68 \\
\hline $\mathrm{CX} 2 \mathrm{~F} 12$ & 0.39 & 12 & 9 & 0.73 & 0.26 & 0.69 & 0.65 \\
\hline CX3B06 & 0.80 & 13 & 11 & 0.36 & 0.21 & 0.36 & 0.42 \\
\hline
\end{tabular}

$\overline{\mathrm{z}} \mathrm{MAF}=$ major allele frequency; GN $=$ genotype number detected; $\mathrm{AN}=$ allele number detected; GD $=$ gene diversity; $\mathrm{H}=$ heterozygosity; PIC = polymorphism information content; F = coefficient of inbreeding. 


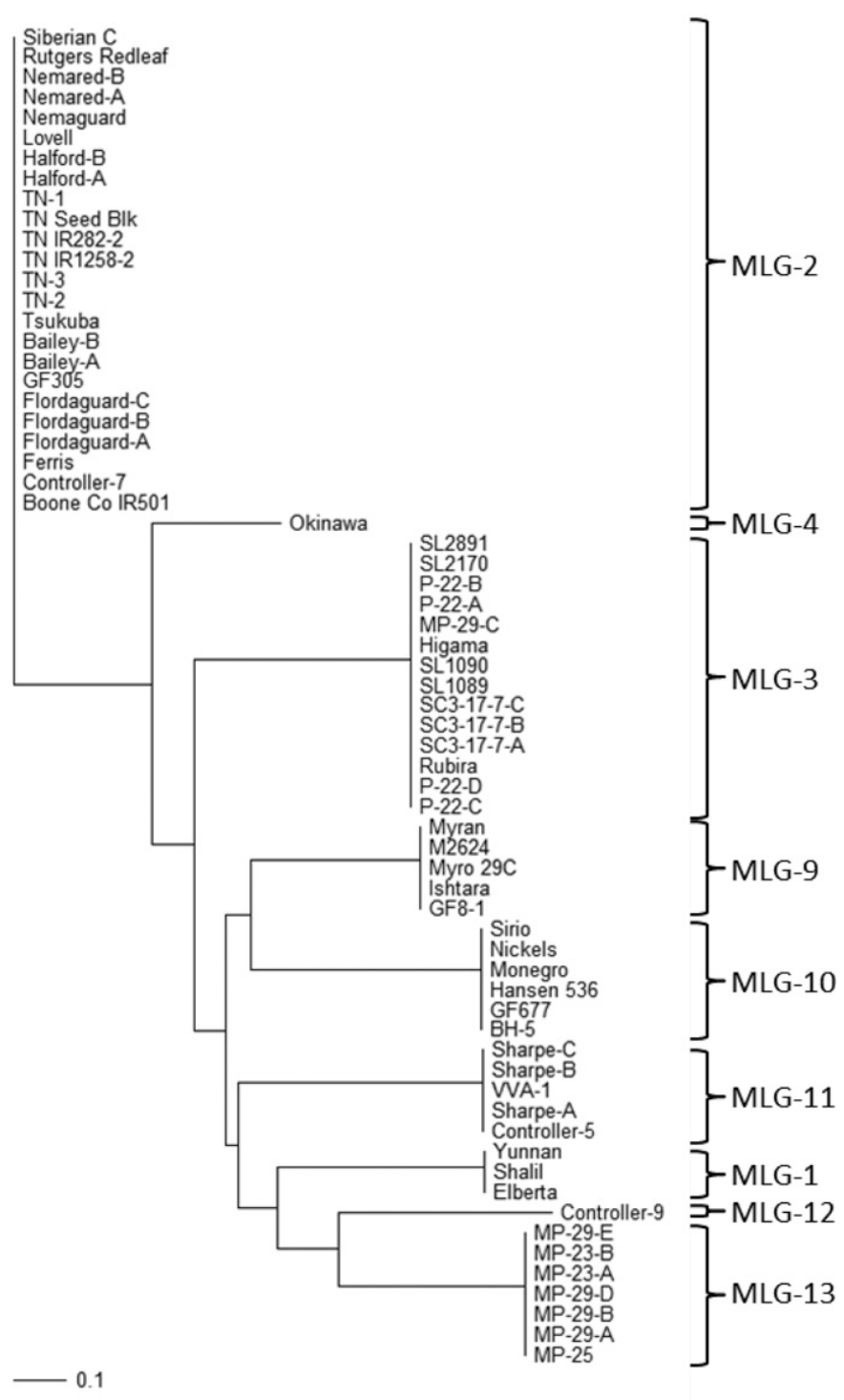

Fig. 1. Neighbor-joining phylogram tree of Prunus rootstock accessions based on chloroplast simple sequence repeat genetic distance pairwise matrixes. Each branch represented a unique maternal lineage group (MLG), including previously defined MLG-1 to -4 and newly discovered MLG-9 to -13 . The bar of 0.1 represents the scale of genetic distances.

many of the oldest American cultivars (i.e., pre-Elberta) associated with European progenitors. Some of them presumably trace back to ancient European peach introductions (Faust and Timon, 1995). A few others were fruiting cultivars that are widely used as rootstocks (e.g., Halford and Lovell). Some of them were also used as maternal parents to breed modern rootstocks, such as 'Flordaguard', 'Nemaguard', and 'Nemared' (Ramming and Tanner, 1983; Sherman et al., 1991). According to a prior report, MLG-2 appeared to be the only maternal group consisting of widely used or well-known rootstocks, ornamentals, and scions (Chen and Okie, 2017), which were all derived from European peach progenitors or progenies. MLG-3 consisted of 'Guardian' rootstock (Okie et al., 1994), and its descendants, such as 'P-22'. MLG-3 also included all Chinese and other Asian ornamental peaches, as previously revealed (Chen and Okie, 2017). 'Okinawa', used as a rootstock as well as a maternal parentage of
'Flordaking' (Andrews et al., 1979; Okie, 1998), was the only member in MLG-4, as observed previously (Chen and Okie, 2017). The new groups, MLG-9 to -13 , represented unique maternal lineages in Prunus, which were presumably defined by the donor genomes from different plums (MLG-9 and MLG-11 to -13) and almonds (MLG-10). MLG-9 had five accessions, including three of the five $\mathrm{MH}$ accessions (i.e., 'GF8-1', 'M2624', and 'Myro 29C') and two of the seven MP hybrids (i.e., 'Ishtara' and 'Myran'), all hybrids of $P$. cerasifera as the seed parent in their pedigree (Table 1), which all fell into the same MLG as expected. The two others of the five MH accessions, 'Sharpe' and 'VVA1', were not from $P$. cerasifera and fell into MLG-11. However, 'Sharpe' had $P$. angustifolia as its questioned parent, whereas 'VVA-1' had P. tomentosa as its maternal parent (Table 1), suggesting the question was warranted, and the parent of 'Sharpe' likely should be $P$. tomentosa unless all the chloroplast alleles at all the loci were the same between $P$. angustifolia and $P$. tomentosa. Of the total six accessions clustered in in MLG-10, 'BH-5', 'Hansen 536', 'Monegro', and 'Nickels' were recorded as the AP type, which were consistent with their pedigree with almond as the seed parent (Table 1); however, 'Sirio' and 'GF677', two only, closely related PA accessions (Table 1), which were not consistent with peach as their seed parent as previously described (Beckman and Cummins, 1991a; Loretti and Massai, 1998). Several early parents and the resulting accessions were open-pollination or chance seedlings of interspecific hybrids, according to their pedigree description in the release notes. The origin of 'Sirio' as the PA type was uncertain and anecdotal and largely based on "morphological characteristics similar to those of a peach $\times$ almond hybrid, although a more complex origin cannot be ruled out..." (Loretti and Massai, 1998). The PA type of 'Sirio' and 'GF677' (i.e., peach as their maternal parent) apparently were not supported by this chloroplast SSR genotyping data. Therefore, 'Sirio' and 'GF677' must be also the AP type unless chloroplasts were paternally inherent from almond or there were other unlikely errors. MLG-13 contained 'MP-23', 'MP25', and 'MP-29' that had the same maternal parent and were supposed to be in the same MLG. In addition, the MP type of 'Controller-5' and 'Controller-9' shared the same maternal parent (i.e., P. salicina) in their pedigree (Table 1) and were supposed to stay in the same MLG. However, 'Controlller-5' was in MLG-11 with $P$. tomentosa or questioned $P$. angustifolia as the presumable maternal parent, whereas 'Controller-9' was alone in MLG-12. Maternal parent inconsistency or contradiction in a few accessions might be due to the uncertain, anecdotal nature of origin or unnoticed erroneous pedigrees or materials. Inclusion of the presumable parents and additional true-to-type accessions in genotyping would lead to clarification. From breeding perspectives, the MLG clusters indicated that the maternal parent of "pure" peach rootstocks was European fruiting peaches (MLG-2) or Chinese ornamental peaches (MLG-3) and their descendants, and that of interspecific hybrid rootstocks was almond (MLG-10) or different wild plum species (MLG-9 and MLG-11 to -13).

Authentication of multiple Clones of the same cultiVARS. Multiple clones of the same cultivars were authenticated based on the pairwise genetic distances among them: zero in the genetic distance value suggested two different accessions/clones were identical. As a result, those identical clones showed zero genetic distance in the phylogenetic trees (Figs. 1 and 2). Among the 15 accessions with multiple clones, 'MP-29'-A was slightly different from B, D, and $\mathrm{E}$ because a new allele was clearly 
Table 3. Maternal lineage groups (MLGs) defined previously by peach and currently by Prunus rootstock accessions and the allele sizes [base pairs (bp)] of the eight chloroplast (cp) simple sequence repeat markers.

\begin{tabular}{|c|c|c|c|c|c|c|c|c|}
\hline \multirow[b]{2}{*}{ MLG no. } & CXcp01488 & CXcp05368 & CXcp36648 & CXcp58614 & CXcp60541 & CXcp62273 & CXcp68964 & CXcp76664 \\
\hline & \multicolumn{8}{|c|}{ (bp) } \\
\hline 1 & 250 & 313 & 308 & 263 & 161 & 262 & 225 & 296 \\
\hline 2 & 255 & 316 & 310 & 264 & 158 & 264 & 225 & 295 \\
\hline 3 & 254 & 314 & 309 & 264 & 160 & 263 & 224 & 295 \\
\hline 4 & 254 & 315 & 309 & 265 & 158 & 264 & 225 & 295 \\
\hline 5 & 255 & 310 & 310 & 264 & 158 & 264 & 225 & 295 \\
\hline 6 & 253 & 310 & 301 & 254 & 142 & 267 & 220 & 298 \\
\hline 7 & 255 & 317 & 303 & 262 & 160 & 260 & 222 & 295 \\
\hline 8 & 261 & 317 & 302 & 262 & 162 & 260 & 224 & 294 \\
\hline 9 & 250 & 316 & 301 & 264 & 159 & 266 & 221 & 306 \\
\hline 10 & 253 & 316 & 301 & 261 & 160 & 269 & 223 & 294 \\
\hline 11 & 255 & 310 & 299 & 265 & 155 & 288 & 221 & 299 \\
\hline 12 & 252 & 313 & 299 & 262 & 154 & 267 & 220 & 301 \\
\hline 13 & 258 & 315 & 301 & 262 & 154 & 263 & 223 & 296 \\
\hline
\end{tabular}

detected at the marker $\mathrm{CX} 3 \mathrm{H} 08$, the only difference from the other clones. We could not give any rational explanation until the only new allele in 'MP-29'-A is further investigated. 'MP29'-C was completely different from the other four 'MP-29' but identical to ' $\mathrm{P}-22$ ' in all chloroplast and nuclear markers used in this study, indicating it is a copy of 'P-22' with little doubt. The discrepancy is likely a sampling error, as ' $\mathrm{P}-22$ ' was located in the row adjacent to the intended sample of MP-29-C.

Phylogenetic Relationships based on nCSSR. Phylogenetic relationships of the collection were revealed in two graphic visualizations (Figs. 2 and 3). As shown in the NJ phylogram tree (Fig. 2), several clusters were revealed and often associated with their parental (primarily maternal) sources. Cluster I included only one peach scion cultivar Elberta from MLG-1. Most accessions in Cluster II, III, and V were derived from peaches found in MLG-2, and Cluster III also included the only cultivar Okinawa from MLG-4. Most accessions in Cluster IV and VI were derived from peaches found in MLG-3 and some of them were related to 'Guardian' rootstock. Cluster VII included most accessions of plum-peach hybrid origin and those found within MLG-13. Cluster VIII was found to be mixed with different plum-peach hybrids and hybrids derived from other Prunus species, most of which were found in MLG-10, -11, and -12. Most accessions in Cluster IX were related to plums in MLG-11 and a few accessions in MLG-9.

The PCoA chart was built based on 44 unique genotypes (Fig. 3), which resulted from removal of all identical genotypes and avoided overlapping of identical samples in the chart. Percentage of variation explained by coordinates 1 and 2 was 31.19 and 9.70, respectively. Eigenvalue of the two coordinates was 0.139 and 0.043 , respectively. The PCoA partition visually showed the phylogenetic distances among the accessions and revealed genetic admixture in many of the accessions in the collections, particularly among those with plum and peach genetic backgrounds in the top-right area (Fig. 3). Most pure peach accessions were spread in the bottom-right area. In the bottom-left area likely were 'Sharpe' and other "pure" plum rootstocks. In the top-left area there were four interspecific hybrids with peach in the parentage, 'Myran', 'Ishtara', 'Sirio', and 'Monegro', which clustered closely to some peaches or MP hybrids in the top-right partition. For instance, 'Myran' was close to 'Yunnan', which was in their paternal parentage.
NCSSR-BASED PCA. The PCA based on ncSSR data showed a closer relationship among the $\mathrm{P}, \mathrm{PA}$, and MP accessions when compared with the five accessions in the MH group (Fig. 4). A wider spread among $\mathrm{MH}$ accessions may be alluding to a greater diversity in this group that is composed of hybrids of different plum species. 'Myro_29C', 'M2624', and 'GF8-1', all in MLG9, clustered together at the top-left area (Fig. 4), as they shared $P$. cerasifera as a maternal parent. On the other hand, 'Sharpe' (A-C) and 'VVA-1' clustered separately from the three $\mathrm{MH}$ accessions but together in the bottom-left area (Fig. 4), suggesting the two genotypes should share the same or closely related parental species in their pedigree. Their close phylogenetic relationships were also exhibited in the cpSSR-based tree (MLG-11) (Fig. 1), the ncSSR-based tree (Cluster IX) (Fig. 2), and the PCoA chart (left-bottom sector) (Fig. 3). However, the plum parents in their pedigree were unrelated (Table 1): 'Sharpe' was a questioned $P$. angustifolia hybrid, whereas 'VVA-1' was a $P$. tomentosa $\times$ $P$. cerasifera hybrid. Therefore, further studies are needed to validate the parentage of the two accessions and better understand the phylogenetic relationships with other $\mathrm{MH}$ accessions.

The PCoA and PCA did not represent much of the variation (e.g., $40 \%$ and 23\%, respectively), which is typical for DNA marker analysis because the information content of the many eigenvectors is usually distributed relatively evenly across many of them. Therefore a two- or three-dimension representation of clustering could only show some of the potential clustering arrangements. Lack of separation in PCA might be due to the limited information content of the first two PCAs. This PCA also suggested that most of the accessions were very closely related (also suggested by the NJ analysis). Consequently, the results could be useful for significantly reducing the size of the collection being maintained at Byron, GA, and the associated cost reductions could be used to introduce additional variations into the collection.

The results gained from this study provided valuable molecular marker knowledge of a rootstock collection maintained at the USDA stone fruit breeding program at Byron, GA, revealing a relatively diverse MLG and phylogenetic relationships and a few accessions with inconsistent maternal parentages showed in the MLGs and pedigrees. Rootstocks are one of the two key biological components for peach production. The MLG and phylogenetic relationship data could be very useful in future breeding 


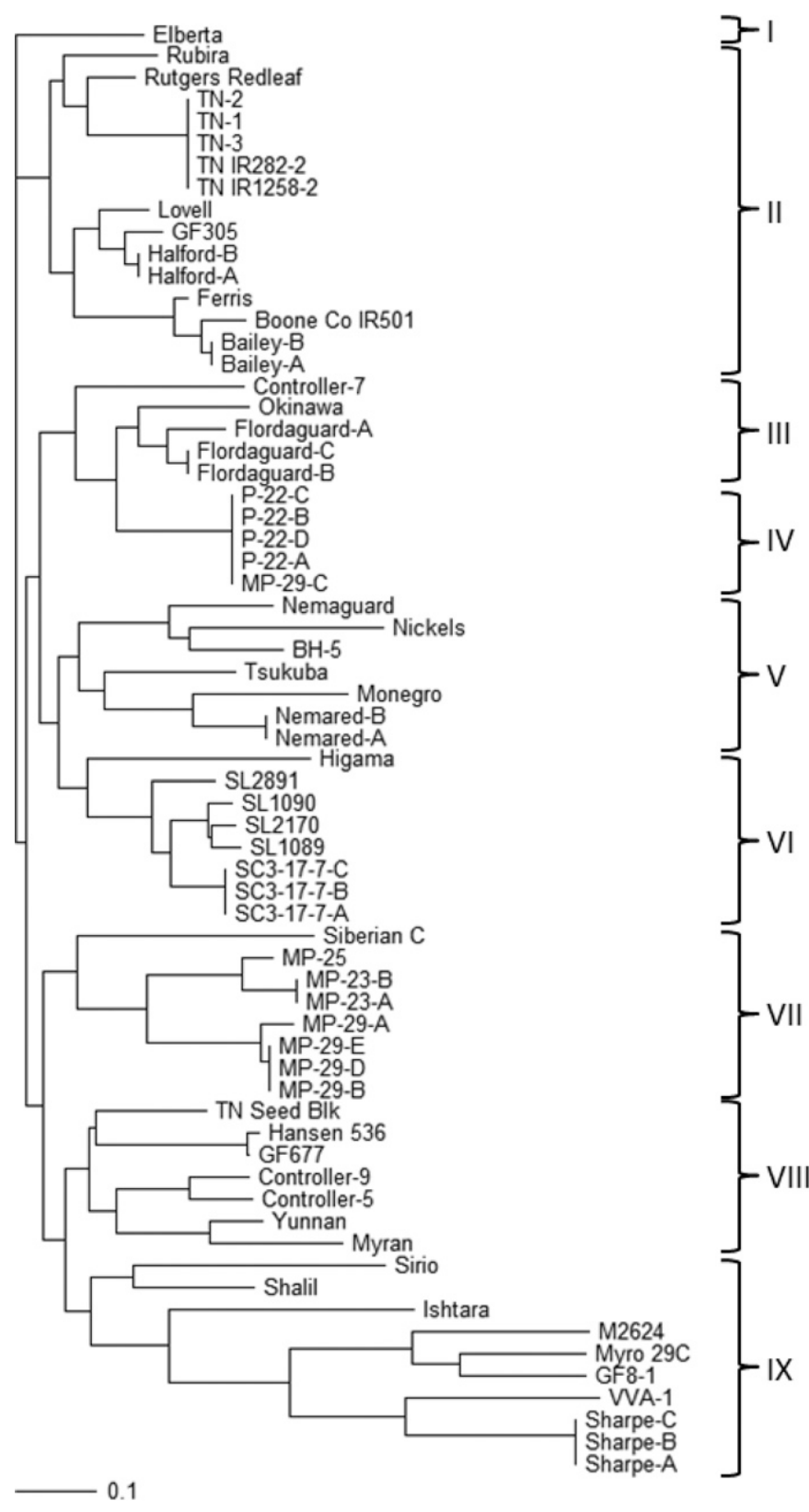

Fig. 2. Neighbor-joining phylogram tree of Prunus rootstock accessions based on nuclear simple sequence repeat genetic distance pairwise matrixes. The bar of 0.1 represents the scale of genetic distances.

and testing of rootstocks with more desired traits needed for commercial peach production, including resistance to soilborne diseases and nematodes, compatibility with scions, ease of propagation, and enhancement of horticultural performances.

\section{Literature Cited}

Andrews, C.P., W.B. Sherman, and P.M. Lyrene. 1979. Flordaking peach. HortScience 14:81-82.

Beckman, T.G. 1998. Outcrossing in a diverse peach rootstock seed block. Fruit Var. J. 52:100-103.

Beckman, T.G. 2004. Prunus rootstock, p. 1516. In: W.R. Okie (ed.). Register of new fruit and nut varieties. List 42. HortScience 39:1509-1523, https://doi.org/10.21273/HORTSCI.39.6.1509.

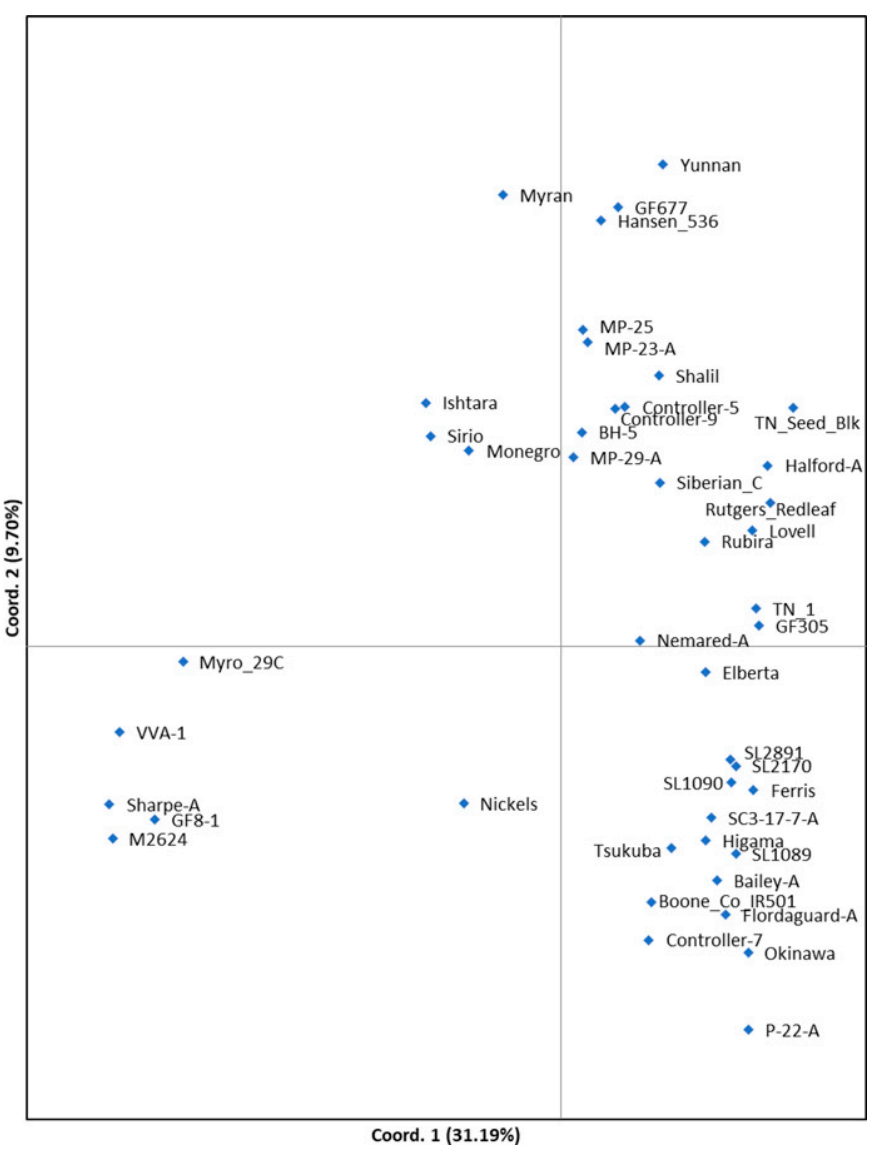

Fig. 3. Principal coordinate (Coord.) analysis of unique Prunus rootstock accessions.

Beckman, T.G. 2006. Peach rootstock, p. 1119. In: J.R. Clark and C.E. Finn (eds.). Register of new fruit and nut varieties. List 43. HortScience 41:1101-1133, https://doi.org/10.21273/HORTSCI.41.5.1101. Beckman, T.G. 2014. Peach rootstock, p. 413. In: K. Gasic (ed.). Register of new fruit and nut varieties. List 47. HortScience 49:396-421, https://doi.org/10.21273/HORTSCI.49.4.396.

Beckman, T.G., J.X. Chaparro, and W.B. Sherman. 2008. 'Sharpe', a clonal plum rootstock for peach. HortScience 43:2236-2237, https://doi.org/10.21273/HORTSCI.43.7.2236.

Beckman, T.G., J.X. Chaparro, and W.B. Sherman. 2012. 'MP-29', a clonal interspecific hybrid rootstock for peach. HortScience 47:128-131, https://doi.org/10.21273/HORTSCI.47.1.128.

Beckman, T.G. and J.N. Cummins. 1991a. Rootstocks for peaches, p. 974-975. In: J.N. Cummins (ed.). Register of new fruit and nut varieties. List 35. HortScience 26:951-986, https://doi.org/10.21273/ HORTSCI.26.8.951.

Beckman, T.G. and J.N. Cummins. 1991b. Rootstocks for plums and prunes, p. 977-978. In: J.N. Cummins (ed.). Register of new fruit and nut varieties. List 35. HortScience 26:951-986, https://doi.org/ 10.21273/HORTSCI.26.8.951.

Beckman, T.G. and J.N. Cummins. 1991c. Rootstocks for almonds, p. 951-952. In: J.N. Cummins (ed.). Register of new fruit and nut varieties. List 35. HortScience 26:951-986, https://doi.org/10.21273/ HORTSCI.26.8.951.

Beckman, T.G. and P.L. Pusey. 2001. Field testing peach rootstocks for resistance to armillaria root rot. HortScience 36:101-103, https://doi.org/10.21273/HORTSCI.36.1.101.

Blenda, A.V., I. Verde, L.L. Georgi, G.L. Reighard, S.D. Forrest, M. Munoz-Torres, W.V. Baird, and A.G. Abbott. 2007. Construction of a genetic linkage map and identification of molecular markers in peach 


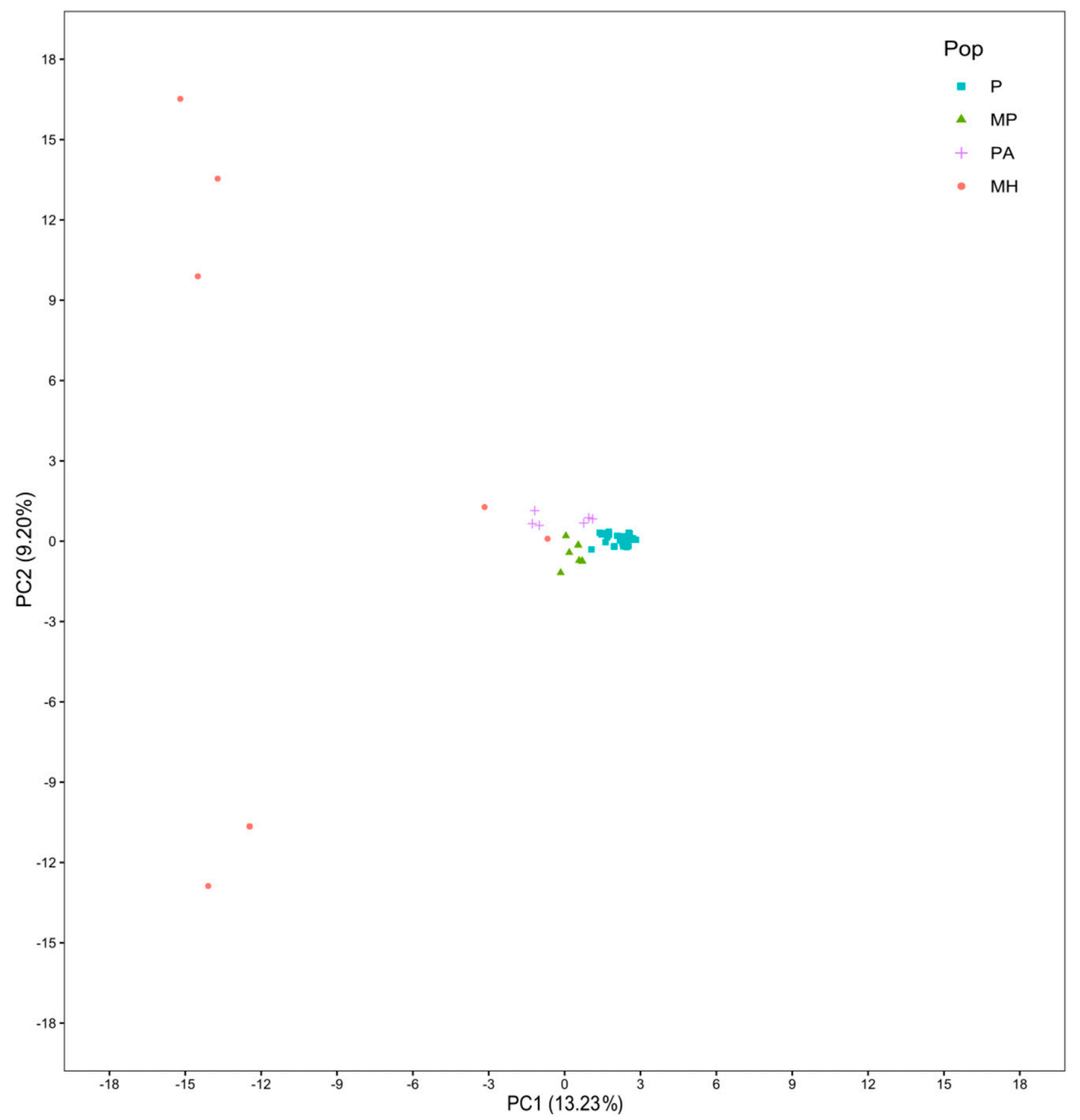

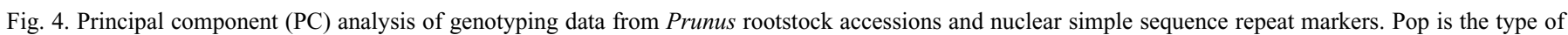
the accessions: $\mathrm{P}=$ peach, $\mathrm{PA}=$ both peach $\times$ almond and almond $\times$ peach hybrids, $\mathrm{MP}=$ plum $\times$ peach hybrids, $\mathrm{MH}=$ plum hybrids.

rootstocks for response to peach tree short life syndrome. Tree Genet. Genomes 3:341-350, https://doi.org/10.1007/s11295-006-0074-9.

Bouhadida, M., A.M. Casas, M.J. Gonzalo, P. Arus, M.A. Moreno, and Y. Gogorcena. 2009. Molecular characterization and genetic diversity of Prunus rootstocks. Scientia Hort. 120:237-245, https://doi.org/10.1016/j.scienta.2008.11.015.

Bright, W., V. Bright, J. Bright, and E. Bright. 2008. Peach-almond hybrid tree named 'Arthur V'. U.S. Plant Patent No. 18,782. Filed 26 June 2006. Issued 6 May 2008.

Brooks, R.M. and H.P. Olmo. 1997. The Brooks and Olmo register of fruit and nut varieties. ASHS Press, Alexandria, VA.

Chen, C., C.H. Bock, W.R. Okie, F.G. Gmitter, S. Jung, D. Main, T.G. Beckman, and B.W. Wood. 2014. Genome-wide characterization and selection of expressed sequence tag simple sequence repeat primers for optimized marker distribution and reliability in peach. Tree Genet. Genomes 10:1271-1279, https://doi.org/10.1007/s11295-0140759-4.

Chen, C. and W.R. Okie. 2017. Characterization of polymorphic chloroplast microsatellites in Prunus species and maternal lineages in peach genotypes. J. Amer. Soc. Hort. Sci. 142:217-224, https://doi.org/ 10.21273/Jashs04070-17.

Chen, C. and W.R. Okie. 2021. Genetic relationship and parentages of historical peaches revealed by microsatellite markers. Tree Genet. Genomes 17:35, https://doi.org/10.1007/s11295-021-01517-8.

Doyle, J.J. and J.L. Doyle. 1987. A rapid DNA isolation procedure for small quantities of fresh leaf tissue. Phytochem. Bull. 19:11-15. 
Faust, M. and B. Timon. 1995. Origin and dissemination of peach. Hort. Rev. (Amer. Soc. Hort. Sci.) 17:331-379, https://doi.org/10.1002/ 9780470650585.ch10.

Felipe, A. 2009. 'Felinem', 'Garnem', and 'Monegro' almond $\times$ peach hybrid rootstocks. HortScience 44:196-197.

Jimenez, S., J. Pinochet, J. Romero, Y. Gogorcena, M.A. Moreno, and J.L. Espada. 2011. Performance of peach and plum based rootstocks of different vigour on a late peach cultivar in replant and calcareous conditions. Scientia Hort. 129:58-63, https://doi.org/10.1016/j.scienta. 2011.03.006.

Jombart, T. 2008. Adegenet: An R package for the multivariate analysis of genetic markers. Bioinformatics 24:1403-1405, https://doi.org/ 10.1093/bioinformatics/btn129.

Kamvar, Z.N., J.F. Tabima, and N.J. Grunwald. 2014. Poppr: An R package for genetic analysis of populations with clonal, partially clonal, and/ or sexual reproduction. PeerJ 2:e281, https://doi.org/10.7717/peerj.281.

Kester, D.E., R.N. Asay, and T.M. Gradziel. 2002. 'Nickels' almond $\times$ peach hybrid clonal rootstock. HortScience 37:415-417, https://doi. org/10.21273/HORTSCI.37.2.415.

Liu, K. and S.V. Muse. 2005. PowerMarker: An integrated analysis environment for genetic marker analysis. Bioinformatics 21:2128 2129, https://doi.org/10.1093/bioinformatics/bti282.

Liu, X., G.L. Reighard, G.A. Swire-Clark, and W.V. Baird. 2007. Peach rootstock identification by DNA-fingerprinting with microsatellite (SSR) markers. J. Amer. Pomol. Soc. 61:162-166.

Loretti, F. and R. Massai. 1998. Sirio: A new peach $\times$ almond hybrid rootstock for peach. Acta Hort. 465:229-236, https://doi.org/10.17660/ ActaHortic.1998.465.28.

Lu, Z.X., G.L. Reighard, W.V. Baird, A.G. Abbott, and S. Rajapakse. 1996. Identification of peach rootstock cultivars by RAPD markers. HortScience 31:127-129, https://doi.org/10.21273/HORTSCI.31.1.127.
Myers, S.C., W.R. Okie, and G. Lightner. 1989. The Elberta peach. Fruit Var. J. 43:130-138.

Okie, W.R. 1998. Handbook of peach and nectarine varieties: Performance in the southeastern U.S. and index of names. U.S. Dept. Agr. Handb. 714.

Okie, W.R., T.G. Beckman, A.P. Nyczepir, G.L. Reighard, W.C. Newall, and E.I. Zehr. 1994. BY520-9, a peach rootstock for the southeastern U.S. that increases scion longevity. HortScience 29:705-706, https://doi.org/10.21273/HORTSCI.29.6.707.

Orazem, P., F. Stampar, and M. Hudina. 2012. Comparison of ten peach rootstocks performance grafted with 'Redhaven'. Eur. J. Hort. Sci. 76:162-169.

Page, R.D.M. 1996. TreeView: An application to display phylogenetic trees on personal computers. Comput. Appl. Biosci. 12:357-358.

Peakall, R. and P.E. Smouse. 2006. GENALEX 6: Genetic analysis in Excel. Population genetic software for teaching and research. Mol. Ecol. Notes 6:288-295, https://doi.org/10.1111/j.1471-8286.2005.01155.x.

Peakall, R. and P.E. Smouse. 2012. GenAlEx 6.5: Genetic analysis in Excel. Population genetic software for teaching and research-an update. Bioinformatics 28:2537-2539, https://doi.org/10.1093/bioinformatics/ bts460.

Ramming, D.W. and O. Tanner. 1983. Nemared peach rootstock. HortScience 18:376.

Sharpe, R.H. 1974. Breeding peach rootstocks for the southern United States. HortScience 9:362-363.

Sherman, W.B., P.M. Lyrene, and R.H. Sharpe. 1991. Flordaguard peach rootstock. HortScience 26:427-428, https://doi.org/10.21273/ HORTSCI.26.4.427.

Wickham, H. 2016. ggplot2: Elegant graphics for data analysis. Springer International Publishing, New York, NY, https://doi.org/ 10.1007/978-3-319-24277-4. 